\title{
Aggression and antisocial behaviors of Teenagers
}

\author{
Ida Kruti \\ European University of Tirana \\ Faculty of Social Sciences and Communication \\ PhD Programs \\ Tel.00355(0)69 2522984 \\ e-mail:ida_t2002@yahoo.de
}

\begin{abstract}
Adolescence, is a period of life that is knowing and studying by many researchers for many years, has always been and remain the subject for many sciences. The adolescence is recognized as one of the most rapid moments of life, full of strong emotions and it is considered as the process of individuals maturing regard to the individual development. In this period of life teenagers will be accompany of the main phenomena as Aggressive and Antisocial behavior, that moment is a disturbing phenomena that is shacked and troubled Albanian family and society, which can appear in the form of verbal or physical. The object of my research is based on literature review of the adolescent aggression and antisocial behavior during development , including theoretical and empirical data in the Albanian society. During valuation is important to identify the functions and forms of aggression and Antisocial Behavior. At the time of dictatorship was talk very little about adolescence, about their desires and emotions. This kind of state cared to grow up the new man, worthy and the service of communist society. While teens studies today are getting more and more spread in our country. The methodology used in this analysis focus on articles, dissertations and current scientific studies of known as well as can the reality and trends of adolescent aggressive behavior in Albanian. Selection criteria include 1. Topics 2. Type of paper (books, magazine, dissertation) 3. Papers methodology 4. Year of publication. Were included in this study 10 books, 30 articles, 30 work degree. Eventually were selected from all of them 5 books, 5 articles and 10 Bachelor and Master degree to be included in this summary. Conclusions: This study is sheds light clearly on the lack of empirical scientific studies on understanding this phenomenon of adolescence Aggression and Antisocial in Albanian society, while these studies are very detailed in the world. The selected current studies have methodological problems and may not be comprehensive for whole Albania areas, where many lifestyle aspects are different. This summary allows raising questions that in the future research may guide right studies in this field.
\end{abstract}

Keywords: Teens, aggression, antisocial behavior, selection criteria, empirical study

\section{Aggression and antisocial behaviors of Teenagers}

The phenomenon of aggression and antisocial behaviors had been studied since the $18^{\text {th }}$ century. If we base to the analyses of the factors, which cause this phenomenon we get to the conclusion that aggression is caused by internal factors ( Instincts Theory S.Freud and K.Lorenz), such us nervous, genetic, biological or chemical, or external, when it is showed like an answer of the frustrating moment(Frustration-Aggression Theory, John Dollar), or like a consequence of a learned behavior( Learning Theory, Bandura). The antisocial behaviors are divided in stable and episodically (Taxonomy Moffit).

All of the human societies, one less and one more based on the historical or social improvements have been faced with these occurrences. Some societies have accepted these occurrences and they have justified them like culture or religion behaviors. For example in the North India a criminal group in 1550-1850 killed more than two thousand people for their empire( Myers, G.D. "Socialpsychologie" 1999). The decade of 90' in USA, Europe and basically in UK and German is famous for the terrible increase of these antisocial behaviors and aggrsession, general in society and specially at teenagers. 
In the USA in 1990 was mentioned that this phenomenon was being decreased, but since that year the number of the teenagers, who were arrested for deliquent behavior was a million per year, a number five times higher than in 1960 (Myers G.D "Socialpsychologie", 1999).

During 1968, 1981, 1995 Berkowitz made experiments with children and students of the Uiscon University, in which he gave to children a toy gun to play, and to students a real gun. The results were almost the same: the children were happy to destroy the other's children toy, and the angry students were more explosived to their "victims", what made him understood that guns creates aggresiveness thoughts (Myers, G.D. "Socialpsikologjia", 1999).

During the years and in different social and culture conditions, empirical studies started to be more specific. In 2002 studies conducted in USA for the physical, verbal and indirect aggressiveness of teenagers, showed that one in five children tease the others, more than one in three high school students have showed physical attack. About $30-40 \%$ of male teenagers and $16-32 \%$ of female had performed violent offenses in the age of 17. (National Youth Violence Prevention Ressource Center, 2002).

According to the empirical studies in USA, in 2008, in which were included 73.498 teenagers that was referred to gender differences, showed that the difference of physical aggression in males was more powerful than the verbal one in females (r. $29 / \mathrm{r}-, 03$ ) and the opposite happened in to verbal aggresiveness, in which $54 \%$ were females. The similar result shows and the last studies of the Ubiversity of California in december of 2012 (Card, A.N. \& Sawalani, M. G. \& Stucky, D. B. \& Little, D. T. "Direct and Indirect Aggression During Childhood and Adolescence: A Meta-Analytic Review of Gender Differences, Intercorrelations and Relations to Maladjustment Direct" 2008, Vol 79, pg. 1185-1225 / Juvonen, J. \& Wang, Y. \& Espinoza, G." Physical Aggresion, Spreading of Rumors and Social Prominence in Eary Adolescence", 2012).

The empirical studies of american teenagers $15-18$ years old in 2011 showed that $32.8 \%$ of them had physical aggression out of school, $40.7 \%$ of them were males and $24.4 \%$ females. While at school had $12 \%$ physical aggresiveness, in which $16 \%$ of them were males and $7.8 \%$ were females ( National Center for Injury Prevention and Control. Division of Violence Prevention 2012).

In Canada had also studies for these occurrences. In one of the studies, very interesting, the one of 2007 for the physical and emotional aggression of the heterosexual teenage couples, showed that $20-50 \%$ of these couples were included in aggressive relations.

The results were based in reports of the girls and the boys, who were aggressive and those who were victims( Conolly, J. \& Josephson, W. "Aggression in Adolescent Dating Relationships. Predictors and Prevention, Integrated Research Services, 2007).

Similar studies were made also in UK. For the period 1985-1995 the results showed a raise of violent crimes in $84 \%$ compared with the past decades(Myers, G.D. "Socialpsichology", 1999). During 2005-2012 based in the datas of killed teenagers in UK showed that $40 \%$ of them were attacked from knives and 6-7\% of them from guns ("Mapping the Location and Victim Profile of Teenage Murders in London 2005 to 2013").

In German up to decade of 90 ' had absence of the empirical research, although formerly this country had experienced some powerful social movements( respectively the student movements in 1950-1960, or those in 1970-1980) that had affected to the history of this nation, they had not commited empirical research. Genuine empirical research were commited during 1990-1998 from the Institution of the Research Centre of Social and Psychological Sciences in the University of Nuremberg, with teenagers of 14-21 age, who showed a high level of antisocial bahaviors and specially of aggressiveness.

This made the government to take some programms which lasted two years for the reduction of aggressiveness in schools. From the studies commited in 2000 , after the completion of the programme, was resulted that the level of aggression in these teeenagers was reduced in $15-30 \%$.

The studies commited from the Criminal Research Institute in cooperation with some universities and university research centers in 2003, as is again in cooperation with the Research Centre of Social and Psychological Sciences in the University of Nuremberg and Kiel, commited with teenagers of $14-18$ age, showed that $43.9 \%$ of them had made physical and verbal aggresion in the internal of school.

This result was based to what students had reported, while $13 \%$ of them were victims of thefts and $8 \%$ were threatened from their peers with knives and guns. While the report of teachers showed that aggressiveness out of school was higher 
than those which were declared. So, from the studies resulted that $61.8 \%$ of teenagers from these schools were part of violent groups out of school. Most of them were males, but the number of females included was also not so low .

( Lösel, F. \& Bliesener, Th. "Aggression und Delinquenz unter Jugendlichen. Untersuchungen von kognitiven und sozialen Bedingungen, May, German, 2003).

A study commited recently from two professors of Faculty of Social Sciences and Psycology in physical and verbal aggressiveness of teenagers in Spain, showed that the physical and verbal aggressioan was higher at males. Verbal aggression resulted to be almost similar, with a very small difference with the females (Pena, R. L. \& Pacheco, E. N. "Physical-Verbal Aggression and Depression in Adolescents: The Role of Cognitive,Emotion Regulation Strategies", Universidad de Málaga, España, May, 2012).

It's very hard to talk about such comprehensive studies and empirical research extended in time and individualized according to adolescent gender in our contry, hier in Albania.

\section{Theoritical framework}

Antisocial behavior is the ability to cause damages or concerns to another person, which is showed to the person at the start of early childhood.

Antisocial behaviors conclude all the vandalists acts, drugs use or another substances such us: inebriety, abusive behavior in public facilities, threatens, racial or gender harassments.

Antisocial behavior is a behavior way against norms of a society.

Parke and Sloby(1983) determines aggression a way or a form of reaction within unsocial bahavior, which is directed to a person with a purpose to damage him. This definition is similar to this that Loeber( specialist of criminal behaviors-1985 pg. 6) had made for the antisocial behaviors, according to which this physical or mental attack has as purpose to cause damage to another person breaking or not the law of criminality.

Antisocial bahaviors are studied more than aggressive ones, because aggressive behavior is seen in context of the antisocial one, including here frauds or tipical antisocial behaviors such us: use of substances ect. Usually aggressiveness and unsocial behavior are considered similar, but in fact has differences between them.

According to some multiyear studies of Blumstein, antisocial behavior is showed with neglect and cause damages to the society and is accompanied with aggressiveness to other people. If in little children is showed evidently nervousness and impulsively, in elderly age they will be prone to make these bahaviors to criminal ones. Violent in this age in 15 recently years is raised very much.

According to Moffitt we have two types of unsocial behaviors:

\section{a. Stable}

Episodically, these are depended from the conditions and the development of the teenage. (Moffitt T.E "AdolescenceLimited and Life-Course-Persistent Antisocial Behavior: A Developmental Taxonomy", Psychological Review (1993). 100 , 674-701)

"Aggression" comes from the word lat. aggredi $\rightarrow$ attack, by which is understood an organism which has the ability to make an aggressive behavior to other people.

"Aggressiveness" is determined as an emotion, which is accompained with a wish to attack other people, which is maybe caused as a consequence of hormonal changes or genetic anomally.(Webster ninth New Collegiate Dictionary).

Aggression can be showed in different moments of our life situations. When the organism manifests this like a protection way, this occurrance would be positive, but when aggressiveness is showed with aggression or using different kinds of tools to destroy the others or ourselves, then it is negative.

According to the psychoanalist of Sigmund Freud and ethologist Konrad Lorenz, supporters of the theory of insticts, all humans have the aggression since they are born, which accompanied with sexuality are important elements for a human development, showed at the behaviors that an individual do. While there are some researchers, who aggression is for them a primar force in which aggression may comes as a reaction or frustration of primar needs. This kind of aggression comes as a result of an iritation, or may be a way to answer against an unplanned attack.

So according to John Dollard in 1930, which is knowed as a hypothesis developer of Frustration-Aggression. 
Aggression or frustration conditions brings as an inevitable response, aggression. This aggression may be: physical, psycologic or social.

While about the way of realization is divided in: Affectiv, instrumental (which has no relation with the emotional one), learned, imitative, biogenetic and territorial. (Conner, D. F, "Aggression and Antisocial Behavior in Children and Adolescents". Research and Treatment. The Guilford Press; 1 edition fq. 15 , 2004).

Albert Bandura, a famous canadian psychologist focused his researches about the aggression in teenagers at the learning theory. Bandura insists on the fact that aggression is a learned behavior. Researching a group of children, he showed that a sight of a person during his violent action makes to the child a desire to turn this to a personal experience. According to him, aggression can be learned, here he talks about the aggressiveness performed on television and media.

The scheme according to Albert Bandura by which aggression is encouraged is:

Model- survey- memorizing- reinforcement-behavior.

According to Leonard Berkowitz, all humans learn the types of effective responses, one of which is the aggressiveness showed in special situations. Aggression may be also:

- Reactiv/ theory of Frustration-Aggression, in which promoter may be social problems, family instability, violent or neuropsyciatric problems which may cause this kind of aggression.

- $\quad$ Proactiv/ theory of learning, has a special role to their later life when starts to be adopted since the primary school.

The combination of these above kinds, there can be eluted that the researchers Hubbard and Simsons brought with teir studies. . (Conner,D.F, "Aggression and Antisocial Behavior in Children and Adolescents". Research and Treatment. The Guilford Press; 1 edition pg. 15, 2004).

In 1970 a group of researchers thought that all those who were born with a more cromozom " $Y$ " are prone to make aggressive behaviors, but today is thought that the testosterone hormon at males and estrogen at females are promoters of aggression.

So when we talk about aggression, his curvu fluctuates from the influence of internal factors and also from life experiences. People with high aggressiveness react easily even from a simply teasement.

It is very important that the words aggressiveness and aggression( which means an action of an aggresive behavior in a responsible way with a purpose to cause to another person damage or to destroy animals) to not be used as synonims of each other.

Aggressivenes and specially the physical one is norm inearly childhood, but it is considered untypicall if it continues in the later childhood and when becomes a teenage. Born aggressivenes which is typicall until 2-3 age, if it will not be educated and not treated in the right way from family and relatives or from the educators, the situation becomes more aggressive and can be acompanied by violent actions as a teenager and later as an adult.

In early childhood, aggressivenes is showed in a verbal form. This situation is almost similar to males and females. This are divided as presentive forms of aggresion, but later aggressivenes becomes as a hidden form. During the development, is very important to understand the commons and the differences between males and females in the nature of aggressiveness. The aggressive showed behaviors are promoted from personal and social relations.

In the psychological arguments is still object of conversations, if this aggressiveness is borned, learned or is showed as a response or frustation of primar needs.

\section{Actual context of the researches of this occurance in Albania}

"Adolescence" ( comes from lat. "adolescere", which means to grow up, is knowed as the period of growing, starts with pubertation and continues to an elderly age). Adolescence has its characteristics depended to culture and can be indentified as period of becoming independ(Bertelsmann "Jugendalters",1995, pg. 12).

In american literature the term "adolescence" is identified since the start of pubert from 13-14 age (Arnold 1980, pq. 22).

In Germany, adolescence is knowed as a development period from 15-24 age.

This period is different to different countries and continents, but in general is similar in life years having only difference from 2-3 years. In the XXI century in an important part of literature "adolescence" is determined as a development period for the 
individual, from a child to an adult, where is projected biological at a teenager an adult, but still not with a responsibility and emotional and social stability.

The world organisation of health determines asolescence as a period age of 10-20 age. Adolescence, this important life period of development, when from a child becomes an adult, has its firs researches since Platon and Aristotel.

According to research Muuss is pretended that "adolescence" term is used for the first time in XVII century. But the researchers of XIX century treated this period only in biologic and social aspect.

The real theories which started to study adolescence are in the recent years of XIX century and in the early years of XX century, in which adolscence was the only moment when an individual can be determined as "Bio-Psycho-Social". To treat the individual in this period is important to be analysed his function in family and society in three dimensions: biological, social and psychological. (Ausubel P. David, 2002 Theory and Problems of Adolescent Development,3 Edition, pq.xxi).

The researches of this special period of life was in high levels during XX century. This happened because of the human evolution in science, technology,environment, geografy and of course in all developments.

For many sciences, not only for psychology adolescence was an objectiv of their researches, determining her as "Pubertation", "Young" and "Adolescence".

For biologists and doctors, in the center of the researchers in which are the physical and organic differences, the determine which use is "Pubertation".

For social researchers, this period of development is knowed as "Young". This because in their researchers they present that the individual experience three levels of life development, childhood, being young and being adult.

For psychologists, this period is determined as "Adolscence", in which in the center of their research they analyse the development and psycho experiences, which are showed during this important period, which is considered as a proceess of individual growing.

Adolescence, one of the most explosive moments of life is full of powerful emotions. This period itself is a suffering process, because the teenage is leaving behind the childhood and goes forward to a way to create a new identity in family and society. These differences are related to with knowledge abilities, with special characteristics, in the emotional aspect and in verbal ability of speaking. The desires and the problems thet they have are almost similar, which are influenced more from biological, culture and social factors. This period is accompanied with problems such us: unsocial behaviors and aggressiveness.

Some of the tipicall symptoms that teenagers have are:

- Humor fluctuate, related in general with the emotional aspect.

- $\quad$ Being closed to themselves

- Changes in hungry and hours of sleeping.

As a result of above symptoms and specially the neglism of these behaviors during this period of adolescence can be accompanied with problematical behaviors such us: alcohol consuming, increased aggressiveness, included in vandalism actions, smoking, use of drugs, conflicts in family,school and society.

A teenage individual lives between his desire for being identified and independent and to be accepted.

During the years of dictature in our country was spoken very little for adolescence, for their desires and emotions. During the dictator years in our contry took care more for the knowledge development of youngs, with a format accepted by the comunism society.

This phenomenon was not typicall only for our society, because is a characteristic of dictatorial societies, in which was accepted the value: "Kill one, scare 10"( Myers G.D. "Socialpsicology", 1999).

Actually the researches for adolescence are trying to be wider and wider, with a tendence to know more for this life period.

One of the basic directions is the study of the occurance of unsocial behaviors and agression in adolescence, which is showed problematic and terrifies more and more family and albanian society.

Some big happenings the recently years were enough to catch many times the attention of researchers, psychologists and all albanian society forward this huge problematic phenomenon. Empirical researchers commited in Albania are very partly, 
focused only in one school, or in only one city. These not only shows methological problems, but researches in whole country, almost not exist.

To understand more about the level and the intensity of aggression in adolescence, in the below research is presented a retell of literature. From the analyse of country researches we can understand even in indirect form the reality and the situation that teenagers are nowdays.

\section{Methodology}

The selection of research was made from us in base of these below.

Firstly as a key word was used "Aggression" and "Antisocial behaviors", but because of a very low number of articles, books and projects was used the term "Adolescence".

Were also used the terms "Violent" and "Criminality of youngs". These books, articles, magazines, projects were selected according to the public year( since 2002) and methodology which was used.

We refered also at projects and publics commited by ISHP(Albania Institute of Publik Health), INSTAT (Albania Instute of Statistics) organisations and institutes which takes care for the development of children. Refering to above criterias, were considered 10 books, 30 articles and 30 thema degrees. From these 70 projects were concluded from the sistematic review 5 books, 5 articles and 5 thema degrees, 15 projects.

\section{Analyse}

In the biggest part of these projects are only descriptive and very few analysed, in general they start with a description of albanian reality as a transist society. Is determined the term adolescence and its typicall characteristics, while focusing in development theories such us:

Physical, psychological, kognitiv and emotional.

The creation of identity is one of the determined factors in the later life of everyone. The role that family and school has in the education and the way we have to bahave with them is very important.

A special place have all the problems that accompanied the develop of a teenage, positive and negative elements and also which are the occurances in which has to focuse society, school and family to reduce them.

An important place have the factors which make the devlop of these factors. In the increasement of antisocial behaviors and aggression of teenagers against the provocatives are brought some examples from literature of Myers, G.D "Socialpsikologjia" 1999, by how an element which raise it, is the high level of testosterone and the consume of drugs. In one of the articles selected both in 2012 for "The influence of violent in media at teenagers" we have a try to bring in attention the consequences which can have on children and in early adolescence, the violent in media.

But also here the facts are taken by empirical studies commited in different places, because similar we do not have in Albania and this according to theory model of Bandura for aggressiveness like a learned model.

In this theory we have to add a risk factor in our society, this of having a huge quantity of guns in many families. Having guns is an added reason to promote violent. Examples and researches in different countries exist. So in 1999 in USA happened 10.000 kills in a year, in the same year in UK 10, while UK that period had four times less guns and 16 times less kills than in USA. In our country after 1997, when a high percent of our population had guns, criminality or kill raised drastically.

One of the empirical datas for albanian teenagers was published from ISHP(Albanian Institut of Public Health) 2010. In this research which was done in 12 prefctures of our country, were concluded 4769 children and teenagers. About $20 \%$ of teenagers from 11-15 age drink alkohol, while about $5 \%$ of them consumed it regularly. In focus were brought the negative consequences which had the consume of alkohol when it is accompanied with consume of drugs and is determined as a factor for aggressive behavior. Another empirical study comes from fondacioni "Albanian Central for Population"which in indirect way makes us understand better the situation of showed aggressiveness. According to this research developed with specialists from ISHP and psychologists is refereed to criminal actions of teenagers. From 121 teenagers who have done criminal actions, 38 of them 17 years old were prisoned, while 29 of them have done criminal actions against each other.

According to the project central for Democratic Education (CDE), during the period of may 2012- june 2013 on "Menagation of aggressiveness in school as an instrument for the creation of a safe environment education for students and youngs" in 
Durres and periferic zones of Tirana. The project gives us datas for the impantation of the manage of project for aggressiveness in school of above zones. What does not exist in this project is the methodology of selection of these zones, it has not datas for how is numbered the level and the intensity of aggressiveness, if it was for verbal,physical, instrumental, emotional, showed or latent. It is also ommited the longevity and the empirical results after the implementation of this project if it had reduct of the aggressiveness level.

A fuller sight of the indirect factors for society and family were they live, develop and create their personality teenagers brings some researches. In the research report for "Against violent of children in Albania" in 2006, made in almost whole country, in Korcë, Vlorë, Gjirokastër, Dibër,Tiranë, Shkodër,Mirditë, Berat, Tepelenë dhe Fier nga Pr. Adem Tamo, Dhori Karaj and UNICEF from the forms of violent, people who use violent, its level. A special role has the find of the roads of the level of violent, because these levels of violent would reflect violent of these children in adolescence but also and in adult age.

In a publish of UNICEF in cooperation with European Comunity and the International Sweedish Agency of Development for the "Criminalization of adults in Albania" analyse of the causes and factors of criminalization of adults in Albania in 2007 for ages 14-16 and 16-18, facts showed for a raise of violent acts from teenagers in 2004 we have only 7 teenagers who had made criminal acts.

In 2005 this number went in 31, while in 6 first months of 2006 from 193 authors of criminal acts such us: Kills, or kill in attent, sexual relations or having guns without permission, 23 resulted untill 14 age, while 170 of them were commited from teenagers until 14 age. 225 other acts resulted commited from teenagers from 14-18 age.

Researches and statistic datas exist. In 2008-2009 resulted that $75 \%$ of children had experienced minimal a form of physical or psychological violent. What is interresting to be mentioned from this project is the fact that violent at youngs from 15-29 age may be 6.6, a number very high compared with the number in Europe, which resulted to be 1.0.

While according to "National Research for violent in family" commited from INSTAT(Albania Institute of Statistics) in 2009 resulted that $57,7 \%$ of children reported to be victim of violent act from a family member, $56.8 \%$ were victims from fists etc, $12.8 \%$ with different objects and $4 \%$ were burn with cigarettes.

The projects in Bachelor, Masterdegree or Phd-works for adolescence and aggression have a tendence to be more concrete with the level of this phenomenon, but because of the difficulty of organisation and colaboration of iniversities with many institutions, these projects usually do not have informations for the research and methodology of their commition. They are usually done at only one school, or at the only one school in a village, some of them concluded only males, what did not show the real situation.

\section{Results}

In the selected researches what is common in the biggest part is the theory treatment. Most of the projects talks only about the characteristics of adolescence and how they can be helped based on the problems that they reflect in this important period of life. On some of the projects are focused the researches commited abroad and they take them as referee sources, but not in an analysed level or camparing them with researches in our country. Most of them list the risk factors, but not analysing them. What is interesting in these projects is that most of them are made by females. The similar thing happens on articles on science magayines, while in these few books that were tried to be about the levels of violent, analysing them and about the levels of criminal actions are males. What is also interesting is that this phenomenon has more interest after 2000. In these empirical studies we can learn about the actual situation of albanian reality and this is only a good start.

\section{Conversation}

Based on the review of research of literature we do not have to tell what do we have to do to make more and more effective our reality in Albania. The researches have to include a wider number of teenagers, including the grades and schools, including the education in primary schools and high schools in the whole place, but with a clear methodology. We need to have a clear view of how many females and males have, how many from the schools or classes have heterogen or homogen popullation, how many come from emigration and how many of them have parents no from Albania. How many of them live with both parents and how many with only one parent because of a divorce or something else. How is their economic situation, the work and the education of their parents, if they are the only child , or if they have sisters and brothers. It would be nice to have a clear view for the aggression in and out of school.

Of course the realisation of this project needs time, groups to make colaborations with universities and their specialised staffs. But it has also its limits, because is too diffcult in Albania to make the parents to colaborate and to accept and let 
their children to be part of these tests, a resistance can may be showed and from teenagers themselves. The biggest problem that we have in our country is also the use of a test, because do not have the standarts test in our contry. While we need to know better about aggressiveness and if it is showed or latent, if it is instrumental emotional or evil.

Should be initiated with sensitization of society, family, the schools and the places where the teens grow and educate. Should start immediately with projects and interventions programs to minimize this phenomens, particulary to support and to assistance teenagers spend this period as stromy and vehement in their lives.

\section{References}

[1] Adams G. R. "Adolescent development" The Essential Readings Wiley-Blackwell;1 edition pg.no.106-133, 21, February, 2000.

[2] Ausubel D. P "Theory and Problems of Adolescent Development" Third Edition, Universe; 3 edition fq.no.4254,179 -183, 232 -243,424-432, 15 November, 2002.

[3] Ayph "Key Data on Adolescence 2013". The Association for Young People's Health, CAN

[4] Mezzanine 32-36 Loman Street London.

[5] Bandura A. "Principles of Behavior Modification" pg.no. 127-137Holt, Rinehart and Winston, 1969.

[6] Berk L. E. „Entwicklungspsychologie“,Pearson Studium - Psychologie, Addison-Wesley Verlag; Auflage: 3, pg.12-23, 545-552,565-580 aktualisierte Auflage, 16. Dhjetor 2004.

[7] Bertelsmann"Jugendalters" pg. 12-18, 1995.

[8] Berkowitz L (1981): On the difference between intemal and extemal reactions to legitimate and illegitimate frustrations: A demonstration. Aggressive Behavior 7/ 83-96.

[9] Berkowitz L (1988): Frustrations, appraisals, and aversively stimulated aggression. Aggressive Behavior 14/ 311.

[10] Berkowitz L (1989): Frustration-aggression hypothesis: Examination and reformulation. Psychological Bulletin 106/59-73.

[11] Card, A.N. \& Sawalani, M. G. \& Stucky, D. B. \& Little, D. T. "Direct and Indirect AggressionDuring Childhood and Adolescence: A Meta-Analytic Revieë of Gender Differences Intercorrelations and Relations to Maladjustment Direct" 2008, Vol 79, pg1185-1225.

[12] CDE Menaxhimi i agresivitetit në mjediset shkollore si një nga instrumentet për krijimin e një mjedisi të sigurt edukues për nxënësit dhe të rinjtë,Tirane, 2013.

[13] Conolly, J. \& Josephson, W. "Aggression in Adolescent Dating Relationships. Predictors and Prevention", Integrated Research Services, 2007.

[14] Connor M. D. \& Daniel F. "Aggression and Antisocial Behavior in Children and Adolescents" Research and Treatment. The Guilford Press; 1 edition pg.no. 1-25,28-31,339- 390,12 korrik, 2004)

[15] CRCA -Albania Children's Human Rights Centre of Albania "Kriminaliteti i të miturve në Shqipëri. Analizë tek të miturit në Shqipëri. Juni 2007, Tiranë. Qendra për mbrojtjen e fëmijëve në Shqipëri.

[16] CRCA " Drejtësia për të miturit në Shqipëri.Një analize e sistemit të administrimit të drejtësisë për të mitur dhe gjendjes së të miturve në konflikt me ligjin në Shqipëri".

[17] Delfos. Martine F."Children and Behavioural Problems" Anxiety, Aggression, Depression and

[18] ADHD - A Biopsychological Model ëith Guidelines for Diagnostics and Treatment. Part I. pg.no.45- 78, Kapitull 4 pg.no.79-92 Kapitull 7 pg.no.158-160 Jessica Kinksley London 2004.

[19] Gerald A. \&Berzonsky, M."Blackwell Handbook of Adolescence“, pg.15- 28,31-40,79 -97,

[20] 2001

[21] Gerald, A.\&Gullota,P.Th "Handbook of Adolescence Behavioral Problems"Evidence-Based

[22] Approaches To Prevention and Treatment", pg. 6-13,19-27,2005,Springer Scince + Bisiness Media.

[23] Gemelli R. J."Normal Child and Adolescent Development". American Psychiatric Pub; 1 Edition, Kap. 1, pg.no. 1-47 (May 1996)

[24] Fend H. "Vom Kind zum Jugendlichen. Der Übergang und seine Risiken "Entwicklungspsychologie der Adoleszenz in der Moderne. Huber vgl.pg.323-330 1990.

[25] Flexner W. "Adolescence "pg. 1-27,93-111, 145-160 Sarup \& Son (24 Jun 2004)

[26] Heuves W."Pubertät" „Entwicklungen und Probleme“ Hilfen für Erwachsene. pg.no.30-40,110- 120 Brandes und Apsel. (Frankfurt am Main 2010)

[27] Juvonen, J. \& Wang, Y. \& Espinoza, G. "Physical Aggresion, Spreading of Rumors and Social

[28] Prominence in Eary Adolescence", Springer Science + Business Media, New York, 